\title{
ANÁLISE BIBLIOMÉTRICA EM PUBLICAÇÕES BRASILEIRAS ASSOCIADAS À TEORIA DAS FILAS E SISTEMAS DE PROCESSOS DE FILAS
}

\author{
Tiago Moreira Bessa (Universidade Federal Rural da Amazônia) tiago-mb@hotmail.comlemail \\ Lais Sousa de Paiva (Universidade Federal Rural da Amazônia) laissousapaiva@gmail.com \\ Diego Moah Lobato Tavares (Universidade Federal Rural da Amazônia) moah6@ hotmail.com \\ Andressa Priscila do Nascimento Melo (Universidade Federal Rural da Amazônia) dessa.priscila12@gmail.com \\ Adilson da Silva Sousa (Universidade Federal Rural da Amazônia) adillsonsousa@outlook.com
}

\section{Resumo}

O presente estudo busca evidenciar como a teoria das filas e simulação de sistemas de processos de filas vem sendo tratada dentro do contexto de produção acadêmica brasileira, para isso foi elaborada uma pesquisa bibliográfica utilizando a base scopus, que é uma importante base de dados de produções acadêmico-científicas. Primeiramente os dados foram trabalhados quantitativamente, em seguida os mesmos foram analisados conforme teor e correlação com o tema a ser desenvolvido. Em uma primeira análise obteve-se um total de 227 resultados e através da aplicação de alguns critérios foram selecionados um total de 227 artigos ciêntíficos brasileiros, Posteriormente foram adotados novos critérios resultando em um total de 71 artigos brasileiros com qualis a 2 ou superior e fator de impacto maior ou igual a 1. Na análise quantitativa dos trabalhos publicados verificou-se as publicações feitas ao longo do tempo bem como os autores com mais artigos publicados e áreas de desenvolvimento da temática, seguidamente foram selecionados para compor a amostra de análise os artigos mais referenciados considerando o mínimo de 30 citações, os quais fora realizada a leitura completa e análise do conteúdo.

Palavras-chaves: (Revisão da literatura; Simulação; Teoria Das Filas)

\section{Introdução}

Ao se falar de oferecimento de um serviço ou produção de um produto imagina-se analogamente a obrigação do cliente esperar para obter aqueles. Porém no mundo contemporâneo oferecer um serviço ou produto de qualidade significa compreender a demanda dos clientes, organizar os sistemas que a controlem e ainda ajustar a capacidade de acolhimento em função da demanda, tendo como consequência a redução da espera e eficiência e eficácia do serviço ou produto ofertado (GIANESE e CORRÊA, 2005)

Todavia, diariamente existem problemas de dimensionamentos de fluxos que podem ser contornados por métodos de estudos. O uso de métodos e modelagens de sistemas tem o 
intuito de dimensionar a quantidade ideal de mão de obra e equipamentos, estabelecendo assim o melhor fluxo do sistema analisado, permitindo ainda um melhor dimensionamento e disposição (layout) homem-máquina. Mas para que isso ocorre se é necessário conhecer e analisar o cenário do sistema, tanto suas características, quanto as características dos envolvidos (PRADO, 2009).

Com isso, surge na Pesquisa Operacional a área de teoria das filas, que utiliza conceitos de processos estocásticos e trata de maneira matemática o estudo e análise de filas. Que vem justamente para analisar o comportamento das filas, adequando as mesmas ao dimensionamento adequado de pessoas, instalações, equipamentos e infraestruturas (CHIN et al. 2014).

As filas estão presentes em nosso cotidiano, seja em hospitais, supermercados, bancos, trânsito, espera de máquinas num processo produtivo para seguirem seus fluxos de produção, ou seja, em qualquer situação em que precisamos esperar por um serviço ou produção de algo. O problema de filas foi primeiramente estudado pelo matemático, engenheiro e estatístico Agner Erlang mediante um problema de redes de telefonia no início do século XX. A Teoria das Filas vem sendo aplicada na solução de problemas relacionados a operações de hospitais, congestionamento de tráfego, fluxo de materiais, entre outros. Os resultados de análise de filas podem ser usados em modelos de otimização, para minimizar a soma dos custos de oferecer um determinado nível de serviço no sistema e a soma dos custos de atrasos ou perdas de usuários. Modelos de filas tem sido aplicado com sucesso em diversos sistemas de produção, particularmente em sistemas de serviços (BATALHA et al., 2008)

Diante disto, a partir do recolhimento teórico firmado em pesquisas de alto impacto de cientifico, este estudo busca fazer uma análise da produção cientifica sobre a Teoria das filas no Brasil, levantadas no portal Periódicos CAPES (Coordenação de Aperfeiçoamento de Pessoal de Nível Superior) através da base SCOPUS, na qual esta é uma base referencial da Editora Elsevier, essa base organiza títulos acadêmicos revisados por pares, títulos de acesso livre, publicações comerciais, páginas web de conteúdo científico, anais de conferências, séries de livros, e patentes de escritórios. Além disso ela dispõe também funcionalidades de apoio à análise de resultados (bibliometria) como por exemplo, identificação de autores e filiações, análise de publicações e de citações e índice H. Cobre as áreas de Ciências Biológicas, Ciências da Saúde, Ciências Sociais e Ciências Físicas. 
Á vista disso, este trabalho justifica-se pela importância em ampliar a discussão sobre a evolução do conceito de teoria das filas relacionadas a estudos desenvolvidos no Brasil. E ainda fazendo um levantamento de artigos publicados de alto valor significativo, fazendo um apontamento da situação ao longo do tempo, mostrando assim a relação do assunto desenvolvido na realidade das empresas e organizações do Brasil.

O presente artigo está estruturado em seções iniciando com uma breve introdução do tema contendo o contexto, motivação e objetivo. A Seção 2 contém os embasamentos teóricos para o estudo, com referências e citações relevantes a respeito do tema central. Na Seção 3 tem-se o detalhamento da metodologia utilizada e a descrição dos caminhos que foram seguidos durante a pesquisa. A Seção 4 abrange os resultados encontrados e a discussão sobre a sua interpretação. Por fim, na Seção 5 são apresentadas as considerações finais e proposta de estudos futuros.

\section{Referencial Teórico}

A composição deste estudo procura através de um escopo conceitual apresentar as principais fundamentações que endereçam ao termo Teoria das Filas, na qual de acordo com (PRADO, 2009) é um método analítico que estuda os parâmetros de uma fila (tamanho médio de fila, tempo de médio de espera, taxa média de utilização do servidor, entre outros), de um sistema real. O assunto aborda-se por meio de fórmulas matemáticas, sendo uma das técnicas da Pesquisa Operacional ela estuda as relações entre as demandas de um sistema e os atrasos que os seus usuários sofrem. Pois é inviável conhecer toda uma demanda de um sistema existente durante um período, portanto a técnica se torna representativa para um determinado intervalo de tempo.

Um sistema de filas caracteriza-se pelos seguintes pressupostos, onde se tem um modelo básico de formação de filas (BRONSON,1985).

a) Modelo de chegada dos usuários: as chegadas na maioria das vezes chegam de modo aleatório, isso significa que o número de clientes que chegam por unidade de tempo varia segundo o acaso;

b) Modelo de serviço: normalmente é especificado pelo tempo de serviço ou seja o tempo em que o servidor realiza o serviço para o usuario. As distribuiçõesde probabilidade descrevem o processo de atendimento com base no tempo de serviço; 
c) Capacidade do sistema: capacidade do sistema de suportar usuarios podendo ser infinita ou finita;

d) Disciplina da fila: é a forma de comportamento na qual os clientes são atendidos pelos usuários. A regra mais aplicada, por exemplo, no setor de serviços é o FIFO (traduzido do inglês significa: primeiro que entra-primeiro que sai), além de outros como o LIFO: primeiro cliente a ser atendido é o que chegou por último, o SIRO: o atendimento aos clientes segue uma ordem aleatória, PRI: o atendimento aos clientes segue uma ou mais prioridades preestabelecidas.

Para Moore e Weatherford (2005) modelos básicos para situações de filas é utilizada a distribuição exponencial ainda chamada também de exponencial negativa usada para representar tempos de atendimento (seguindo uma distribuição contínua). O processo de chegada representado pela distribuição de Poisson faz o ajuste do número de chegadas em um determinado intervalo de tempo, de modo que este possui uma relação com a distribuição exponencial.

Conforme Andrade (1990) um sistema de filas é composto de muitos elementos que querem ser atendidos em um posto de serviço e que, eventualmente, devem esperar até que o posto esteja disponível. Prado (2009), afirma que numa fila temos que, de uma certa população, surgem clientes que formam uma fila e que aguardam por um tipo de serviço. O termo cliente pode designar tanto uma pessoa, um navio ou um lingote e o atendimento é constituído por um ou mais servidores (atendentes ou canais de serviços). De acordo com Batalha et al. (2008) os sistemas de filas podem ser classificados como:

a) Sistema de fila única e um único servidor;

b) Sistema de fila única e múltiplos servidores em paralelo;

c) Sistema de múltiplas filas e múltiplo servidores em paralelo;

d) Sistema de fila única e múltiplos servidores em série.

Os modelos de filas e redes de filas são motivados por casos em que os processos de chegada ou serviço, ou ambos, são probabilísticos, resultando na formação de filas de espera e/ou perda de usuários (ARENALES et al., 2011). 


\section{Metodologia}

Para desenvolvimento desta pesquisa primeiramente foi elaborado um estudo bibliométrico através do Portal CAPES por meio da base de dados SCOPUS, esta foi escolhida por possuir um acervo bem amplo de conteúdo científico de grande relevância tanto nacional quanto internacional. Este primeiro momento teve como objetivo a verificação do quantitativo de materiais a respeito do tema proposto e a seleção dos materiais para posterior exploração do conteúdo. Para tanto foram feitos filtros dentro do portal SCOPUS com a temática da pesquisa, adicionando as palavras chaves: queing theory, queue, queuing system, selecionando as publicações de todos os anos, que retornaram um quantitativo de 58.295 artigos.

Posteriormente fora aplicado um segundo filtro de acordo com as categorias de pesquisa adotadas na SCOPUS, para limitar os materiais de pesquisa apenas a artigos de revistas publicados por brasileiros. Em seguida outros importantes filtros foram aplicados sendo estes o fator de impacto (do Journal Citation Reports - JCR) maior ou igual a 1 e Qualis (da Coordenação de Aperfeiçoamento de Pessoal de Nível Superior do Brasil (CAPES) de B1, A2 e A1, que retornaram um total de 71 artigos que atendiam esses requisitos. Em um momento posterior a aplicação de mais um filtro mostrou-se necessária sendo que este consiste na leitura dos resumos dos 71 artigos selecionados, pois dentre esses ainda havia materiais que destoavam do objetivo principal deste estudo como materiais que enfatizavam problemas de eurística e flow shop, por exemplo.

Então chegou-se ao objetivo desta etapa (informações consolidadas sobre o tema) com 45 artigos, através de uma revisão sistemática, com intuito de verificar os artigos com maiores citações e por fim fazer a análise do conteúdo dos mesmos. As etapas da seleção dos estudos estão ilustradas na Figura 1.

Figura 1 - Metodologia.

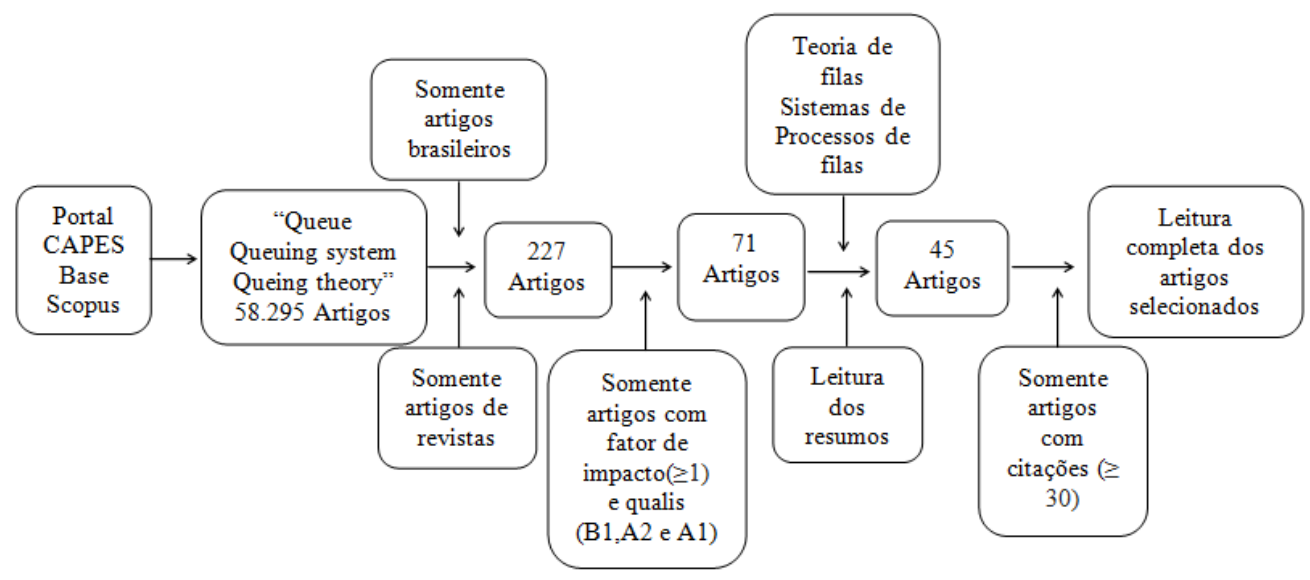




\section{Análise dos dados}

Esta seção contém os principais resultados encontrados na pesquisa feita na plataforma SCOPUS, destacando discussões acerca da temática buscando entender como vem sendo abordada a evolução e dimensão da Teoria das Filas e Sistemas de Processos de Filas no contexto de publicações brasileiras.

\subsection{Análise quantitativa}

Para a análise quantitativa levantados referentes ao número de publicações durante os anos levou-se em consideração apenas artigos com fator de impacto maior ou igual a 1 e qualis B1,A2 e A1, totalizando 71 artigos (100\%). Os dados apresentados a seguir na figura 1, mostram o crescimento de investigações científicas e estudos sobre Teoria das Filas e Sistemas de Processos e Filas no Brasil, conforme abaixo:

Figura 2: Quantitativo de publicações por anos

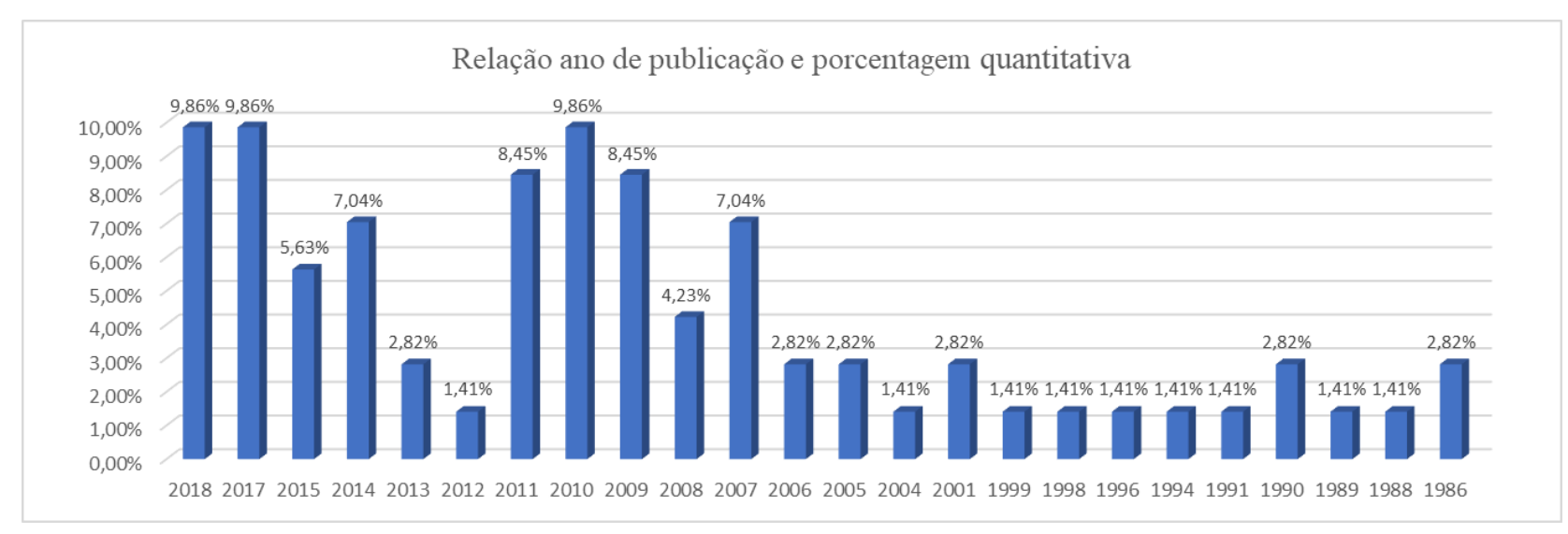

Fonte: Base SCOPUS, adaptada pelos autores, 2019

A partir da figura 1 revela-se que os anos com o maior número de publicações são os anos de 2017 e 2018, com 7 publicações cada um. Esses estudos veem sendo incorporada nas diversas esferas dos meios como: ciencias da computação $(27,5 \%)$, matemática $(23,4 \%)$ e engenharia $(22,2 \%)$ do total 71 artigos, conforme o gráfico da figura 3.

Figura 3: Documentos por área de assunto 


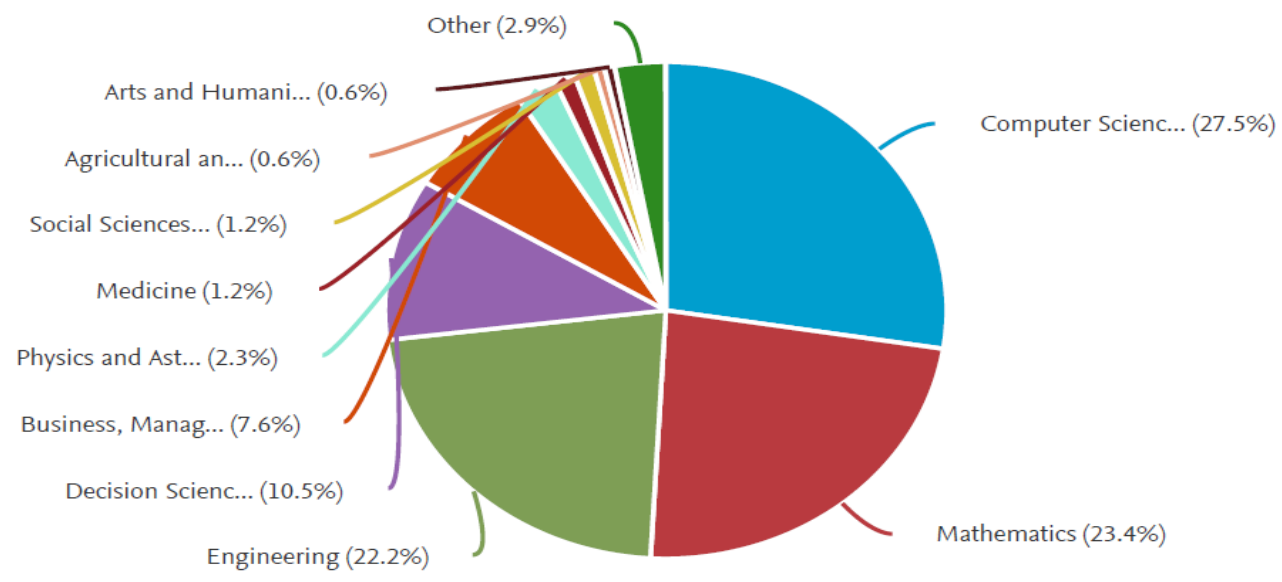

Fonte: Base SCOPUS, 2019

Os valores mostram que as áreas ligadas à computação e engenharia muito possivelmente desenvolvem mais esses estudos e pesquisas relacionadas a Filas, por conta do auxílio do uso das tecnologias e inovação, na qual possibilitam a simulação de situações de filas e processos de filas. Entretanto, a área da matemática segue para melhor entender os cenários dos cálculos gerados com as fórmulas matemáticas dos assuntos envoltos também por novas possibilidades tecnológicas que podem mudar o contexto atual da forma na qual o assunto é tratado e abordado.

Observa-se que os estudos de Filas ganham espaço em particular nestes cenários citados anteriormente, pois se tratam de meios na qual podem auxiliar na melhoria da organização, gestão de fluxos de materiais e informações e congestionamento de tráfego. Nota-se o avanço em temas, como a ciência da computação, que podem potencializar o fluxo de objetos e melhorar a relação entre os ambientes físicos e virtuais.

Foi observado que referente ao número de publicações os autores que têm maior quantidade de publicações é Cuz F.R.B com 11 artigos publicados dos 71 encontrados com os filtros aplicados, conforme explicitado na metodologia, outro autor consagrado que tem até publicação de livro intitulado: Pesquisa Operacional para cursos e engenharia, é Morabito R. com 9 artigos publicados, conforme quadro 1:

Quadro 1: Quantitativo de publicações de autores 


\begin{tabular}{|l|c|}
\hline \multicolumn{1}{|c|}{ Autores } & Quantidade \\
\hline Cruz F.R.B. & 11 \\
\hline Morabito R. & 9 \\
\hline de Souza e SilvaE. & 5 \\
\hline Iannoni A.P. & 5 \\
\hline Van Woensel T. & 4 \\
\hline Chiyoshi F.Y. & 3 \\
\hline Da Fonseca N.L.S. & 3 \\
\hline Kerbache L. & 3 \\
\hline Muntz R.R. & 3 \\
\hline Saydam C. & 3 \\
\hline Smith J.M. & 3 \\
\hline Arruda E.F. & 2 \\
\hline Boffey B. & 2 \\
\hline De Carvalho S.V. & 2 \\
\hline Duarte A.R. & 2 \\
\hline Galvão R.D. & 2 \\
\hline Lavenberg S.S. & 2 \\
\hline Marianov V. & 2 \\
\hline Montez C. & 2 \\
\hline Quinino R.C. & 2 \\
\hline Rodrigues L.F. & 2 \\
\hline Ronconi D.P. & 2 \\
\hline OUTROS (152) & 1 \\
\hline
\end{tabular}

Fonte: Base SCOPUS, adaptada pelos autores, 2019

Após a leitura dos resumos de todos os 71 artigos, realizou-se o refinamento destes, contado apenas os artigos que se relacionavam diretamete com a temática abordada de Teoria das filas e Sistemas de Fials restando apenas 45 artigos, assim foi feito o levantamento da amostra de 5 (cinco) artigos desses 45. Esses 5 artigos tiveram como critério para serem selecionados os artigos com número maior ou igual a 30 (trinta citações) ao longo do tempo. Essa citação se trata do índice $\mathrm{H}$, na qual são calculadas a partir do número de publicações feitas dentro da plantaforma SCOPUS referenciando tal obra.

O Quadro 2 abaixo contém o total e média de citações dos autores com suas respectivas publicações em todo o período abordado na pesquisa, ou seja, desde 1986. 
Quadro 2: Total de citações dos artigos dos autores na plantaforma SCOPUS.

\begin{tabular}{|c|c|c|c|c|}
\hline $\mathbf{N}^{\circ}$ & Autores & Título do artigo & $\begin{array}{c}\text { Ano da } \\
\text { publicação }\end{array}$ & $\begin{array}{l}\text { Total } \\
\text { de } \\
\text { citações }\end{array}$ \\
\hline 1 & $\begin{array}{l}\text { Iannoni } \\
\text { A.P., } \\
\text { Morabito } \\
\text { R., Saydam } \\
\text { C. }\end{array}$ & $\begin{array}{l}\text { An optimization approach for ambulance } \\
\text { location and the districting of the response } \\
\text { segments on highways. } \\
\text { (Tradução: Uma abordagem de otimização para } \\
\text { localização de ambulâncias e distribuição de } \\
\text { segmentos de resposta em rodovias) }\end{array}$ & 2009 & 75 \\
\hline 2 & $\begin{array}{l}\text { Takeda } \\
\text { R.A., } \\
\text { Widmer } \\
\text { J.A., } \\
\text { Morabito R. }\end{array}$ & $\begin{array}{l}\text { Analysis of ambulance decentralization in an } \\
\text { urban emergency medical service using the } \\
\text { hypercube queueing model. } \\
\text { (Tradução: Análise da descentralização de } \\
\text { ambulâncias em um serviço médico de } \\
\text { emergência urbana utilizando o modelo de fila } \\
\text { hipercubo) }\end{array}$ & 2007 & 66 \\
\hline 3 & $\begin{array}{l}\text { Iannoni } \\
\text { A.P., } \\
\text { Morabito R. }\end{array}$ & $\begin{array}{l}\text { A discrete simulation analysis of a logistics } \\
\text { supply system. } \\
\text { (Tradução: Uma análise de simulação discreta } \\
\text { de um sistema de suprimento logístico) }\end{array}$ & 2006 & 57 \\
\hline 4 & $\begin{array}{l}\text { Mendonça } \\
\text { F.C., } \\
\text { Morabito R. }\end{array}$ & $\begin{array}{l}\text { Analysing emergency medical service } \\
\text { ambulance deployment on a brazilian highway } \\
\text { using thehypercube model. } \\
\text { (Tradução: Analisando a implantação de } \\
\text { ambulâncias de serviços médicos de } \\
\text { emergência em uma rodovia brasileira usando } \\
\text { o modelo hipercubo) }\end{array}$ & 2001 & 56 \\
\hline 5 & $\begin{array}{l}\text { Cruz F.R.B., } \\
\text { Duarte } \\
\text { A.R., van } \\
\text { Woensel T. }\end{array}$ & $\begin{array}{l}\text { Buffer allocation in general single-server } \\
\text { queueing networks. } \\
\text { (Tradução: Alocação de buffer em redes de } \\
\text { filas de servidor único em geral) }\end{array}$ & 2008 & 30 \\
\hline
\end{tabular}
Fonte: Elaborado pelos autores, 2019

Os dados permitem destacar que os autores Iannoni A.P., Morabito R., Saydam C. com o artigo "An optimization approach for ambulance location and the districting of the response segments on highways" publicado em 2009, obteve o maior número total de citações da amostra somando 75. Permitindo inferir que o assunto Teoria das filas é muito evidenciado na sistemática da pesquisa. A subseção seguinte irá fazer a análise desses 5 (cinco) artigos, obtidos na plataforma SCOPUS, observando a forma e a abordagem feita pelos autores desenvolvidas no Brasil. 


\subsection{Análise de Conteúdo}

A análise de conteúdo foi elaborada com base nos artigos mais citados considerando artigos com 30 citações ou mais, o que totalizou um quantitativo de cinco artigos provenientes da base de dados scopus.

Entre a amostra selecionada o artigo com a maior quantidade de referências foi Iannoni et al. (2009), com 75 citações. Em seguida Takeda et al. (2007), com 66 citações, seguido por Iannoni e Morabito (2006), 57 citações e Mendonça e Morabito (2001) com 56 e Cruz et al. (2008) com um total de 30 citações.

Iannoni e Morabito (2006) enfatizam em seu trabalho a importância da logística na indústria agrícola sob a ótica do processo de gerenciamento da colheita e transporte tendo em vista do problema de filas durante as fases do processo. O mesmo faz uso da simulação como aliada no processo de resolução do problema na agroindústria da cana de açúcar.

No segundo trabalho mais citado o Iannoni et al. (2009) os autores abordam o problema de filas através do modelo hipercubo de enfileiramento, exemplificando o método desenvolvido por meio de estudo de caso para designar a melhor maneira de disposição de ambulâncias em uma rodovia de modo a otimizar o atendimento as pessoas reduzindo o tempo de espera e auxiliando uso equilibrado dos recursos. Neste estudo os autores abordam o problema de filas por duas óticas e as consideram para a resolução.

Os autores Mendonça e Morabito (2001) também analisaram a melhor maneira de distribuir ambulâncias em uma rodovia brasileira no ano de 2001. Este trabalho publicado pelo autor teve ênfase na redução do tempo de espera da ambulância, visando reduzir o intervalo entre a chamada e o atendimento no local. Os mesmos também fizeram uso do modelo hipper cubo.

A teoria de filas é uma área de bastante abrangência e o desenvolvimento de estudos aplicados em áreas distintas indica a necessidade e importância do estudo para auxiliar o processo de melhoria nas diversas áreas. $\mathrm{O}$ crescente desenvolvimento da teoria de filas denota um refinamento e otimização no processo de melhoria contínua.

O artigo de Cruz et al. (2008) trata da resolução de problema de enfileiramento de difícil resolução, o autor cita como exemplo de aplicação o setor de telecomunicações, manufatura e manuseio de materiais. O mesmo relata três objetivos a serem atingidos através do estudo desenvolvido, sendo o principal objetivo o desenvolvimento de um algoritmo que resolva tipos mais simples de filas de redes finas de enfileiramento de baffer. 
Analisando o último artigo selecionado os autores Takeda et al. (2007) também tratam da teoria de filas enfatizando os benefícios quando a teoria de filas é voltada para questões do serviço de saúde. Neste trabalho os autores utilizaram o modelo hipercubo para analisar a melhor configuração de disposição de ambulâncias do SAMU, que até então se encontravam concentradas em apenas um local, o que dificultava o atendimento nas localidades mais distantes.

\section{Considerações Finais}

Neste estudo identifica-se que a temática de teoria das filas e sistemas de processos de filas em artigos de revistas publicados na plataforma SCOPUS no que se discerne no contexto brasileiro, as publicações mostraram que existe um crescente desenvolvimento de pesquisas desse ramo ao longo do tempo feitas por autores renomados, aplicados a diferentes áreas de conhecimento tais como engenharia e ciencias da computação e programação.

Foi possível perceber também que as publicações se associam a mobilidade urbana e logística e problematicas mais complexas de transporte, apoiada por tecnologias e simulação, e pouco sobre a aplicação em abientes tradicionais como filas de bancos ou supermercados. Com a amostra do material científico selecionado com publicações significativas em revistas com impacto relevante, foi possível identificar que ainda há muito a ser estudado sobre o contexto de Filas em diferentes áreas, principalemnte por estudiosos e autores renomados, como por exemplo em casos de bancos, supermercados, lotéricas, estacionamentos de grande porte. Em especial por ser um assunto muito estudado e desenvolvido por meio de simulação e computação isso norteia que com o avanço da tecnologia possa possibilitar o avanço e melhoria das pesquisas e estudos do tema.

A teoria de filas apesar de ter inúmeras áreas para atuação e trazer grandes benefícios ainda é pouco explorada no Brasil, o quantitativo de materiais de pesquisa com grau de relevância mais elevado atualmente é pequeno. É importante ressaltar que apesar de limitada boa parte desse material desenvolvido é na área da saúde o que indica possível melhoria do serviço relacionado a esse setor futuramente. 


\section{REFERÊNCIAS}

ABENSUR, E. O. Banking operations using queuing theory and genetic algorithms. Produto \& Produção, v.12, n.2, p.69-86, 2011

ANDRADE, E. L. Introdução à Pesquisa Operacional. Rio de Janeiro: LTC, 1990.

ARENALES, M. et al. Pesquisa Operacional. Rio de Janeiro: Elsevier: ABEPRO, 2011.

BATALHA, M. O. et al. Introdução à engenharia de produção. Rio de Janeiro: Elsevier: Campus, 2008.

BRONSON, Richard. Pesquisa Operacional. São Paulo: McGraw-Hill, 1985.

CHIN, S. Y. et al. Aplicação da Teoria das Filas em um Centro de Atendimento de Saúde em Ponta Grossa. In: Encontro Nacional de Engenharia de Produção, 34., Curitiba, Anais... Curitiba: Abepro, 2014.

CRUZ F.R.B., DUARTE A.R., VAN WOENSEL T. Buffer allocation in general single-server queueing networks. Department of Statistics, Federal University of Minas Gerais, Brazil, 2008

GIANESI, I. G. N.; CORRÊA, L. H. Administração Estratégica de Serviços: operações para a satisfação do cliente. Bookman, Porto Alegre, 2005.

IANNONI A.P., MORABITO R., Saydam C.An optimization approach for ambulance location and the districting of the response segments on highways. Department of Production Engineering, Federal University of Sao Carlos,Brazil. European Journal of Operational Research Volume 195, Issue 2, 1 June 2009.

IANNONI A.P., MORABITO R. A discrete simulation analysis of a logistics supply system. Department of Production Engineering, Federal University of Sao Carlos, 13565-905 Sao Carlos, SP, Brazil,2006.

MOORE, Jeffrey H. \& WEATHERFORD, Larry R. Tomada de decisão em administração

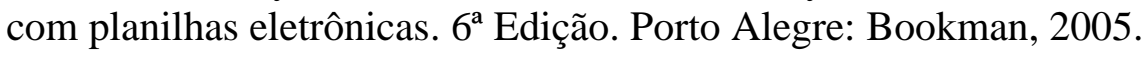

MENDONÇA F.C., MORABITO R. Analysing emergency medical service ambulance deployment on a brazilian highway using thehypercube model. Departamento de Engenharia de Produgao, Universidade Federal de São Carlos, Caixa Postal 676, Brazil, 2001.

PRADO, D. Teoria das filas e da simulação. 4. ed. Nova Lima: INDG Tecnologia e Serviços Ltda, 2009.

ROMERO, C. M.; SALES, D. S.; VILAÇA, L. L.; CHAVEZ, J. R. A.; CORTES, J. M. Aplicação da teoria das filas na maximização do fluxo de paletes em uma indústria química. Pesquisa Operacional para o Desenvolvimento, v.2, n.3, p.226-231, 2010 
TAKEDA R.A., WIDMER J.A., MORABITO R. Analysis of ambulance decentralization in an urban emergency medical service using the hypercube queueing model. Departamento de Engenharia de Produção, Universidade Federal de São Carlos, Brazil,2007 